\title{
Tolerance and response of silver perch Bairdiella chrysoura to hypoxia
}

\author{
Marc H. Hanke $e^{1,2, *}$, Kelly J. Smith ${ }^{1}$ \\ ${ }^{1}$ University of North Florida, Department of Biology, 1 UNF Dr., Jacksonville, Florida 32224, USA \\ ${ }^{2}$ Present address: Department of Biology and Marine Biology, University of North Carolina Wilmington, 601 S. College Road, \\ Wilmington, North Carolina 28403, USA
}

\begin{abstract}
Silver perch Bairdiella chrysoura are an abundant and ecologically important species that are exposed to major hypoxic events throughout much of their range. Acute sensitivity tests $(24 \mathrm{~h})$ were conducted, and the lethal concentration of low dissolved oxygen (DO) determined for B. chrysoura (mean $\pm \mathrm{SE}$ ) $32.5 \pm 4.0 \mathrm{~mm}$ standard length (SL) at $1.10 \mathrm{mg} \mathrm{l}^{-1}$ (95\% CI, 0.43-1.52 mg $\mathrm{l}^{-1}$ ). The avoidance by $B$. chrysoura to low DO was tested based on size class (mm SL): $\leq 25$, between 26-50, 51-75, and $\geq 76$, with normal DO concentrations (control) throughout a partitioned aquarium, and later, with an oxygen gradient from low DO $\left(<1 \mathrm{mg} \mathrm{l}^{-1}\right)$ up to high DO $\left(>5 \mathrm{mg} \mathrm{l}^{-1}\right.$ ). There was a significant difference between the expected and observed distribution for the 3 smaller size classes towards higher DO levels, while the largest size class showed no significant difference in distribution and a $G$-test showed that oxygen choice levels were significantly different between size classes. The 3 largest size classes of $B$. chrysoura were tested in a swimming speed apparatus under 3 current speeds $\left(0.17,0.25\right.$, and $\left.0.36 \mathrm{~m} \mathrm{~s}^{-1}\right)$ with both high DO and low DO concentrations. A 3-way ANOVA showed that there was a significant increase in swimming capacity with increasing fish size, decreasing current speed, and increased DO, as well as a significant interaction between all 3 variables. This is one of the first studies to examine size-related responses to low DO in a sciaenid fish.
\end{abstract}

KEY WORDS: Silver perch - Hypoxia - Low DO tolerance • Avoidance · Swimming capacity • Size class

\section{INTRODUCTION}

Hypoxia is an episodic environmental condition that is becoming more frequent within estuaries of the southeastern United States (Diaz \& Rosenburg 1995, Breitburg 2002, Wu 2002). This increased prevalence is attributed to increased summer temperatures from global warming, nutrient enrichment, and changes in hydrology from dredging for shipping channels (Burton et al. 1980, Breitburg 1992, Eby \& Crowder 2002). Avoidance of low dissolved oxygen (DO) is vital for the success of individual estuarine fish and local populations because fish that survive low DO can recolonize areas of disturbance (Breitburg 1992). It has been well documented that sciaenid fish avoid and can survive in hypoxic waters within an estuarine environment (Pihl et al. 1991, 1992, Eby \& Crowder 2002, Bell \& Eggleston 2005, Tyler \& Targett 2007) as well as in the laboratory (Wannamaker \& Rice 2000, Stierhoff et al. 2009). Different life history stages of fishes within the sciaenid family utilize different habitats for feeding and predator avoidance. As fish grow in size, they move to new habitats with larger prey and increased protection from predators (McMichael \& Peters 1989). Despite changes in habitat use, little work has been conducted on how sciaenids avoid low dissolved oxygen (DO) across their ontogeny. Silver perch Bairdiella chrysoura is a numerically dominant species in estuaries along the Atlantic and Gulf coasts of the 
United States and Mexico (Crabtree \& Dean 1982, Rooker et al. 1998, Peterson et al. 2000, Kupschus \& Tremain 2001, Castillo-Rivera et al. 2002, Hurst et al. 2004, La Peyre \& Birdsong 2008). They are one of the top 5 most abundant sciaenids within this range (Waggy et al. 2006) and are ecologically important because of their abundance and vital role in energy transfer within these estuaries (Kleypas \& Dean 1983). However, they have received little scientific attention regarding their life history (Waggy et al. 2007) and responses to environmental disturbances or stressors. This study utilizes the lower St. Johns River (LSJR), Florida, USA, as an example of a southeastern estuarine system with 2 distinct spatial and temporal low DO events that could impact all ontogenetic stages of B. chrysoura (Hanke 2009). The first low DO event in the St. Johns River happens in late May to June, in the lower oligohaline stretch of the river. The second event within the LSJR occurs later during July to August in the meso/polyhaline zone of the river, where the salinity regime switched from oligohaline to mesohaline. Both of these hypoxic events occur in areas of high densities of B. chrysoura (FWRI 2008; Hanke 2009). Due to the timing and location of these events, all life history stages of $B$. chrysoura could be impacted through direct mortality from low DO or mortality from predators that take advantage of high densities of prey within restricted habitats. To survive these hypoxic events, $B$. chrysoura need to be able to tolerate the low DO levels or move out of the impacted area. Recent work on juvenile estuarine fish has shown that with decreasing DO levels, fish will increase their swimming activity. With decreasing DO levels, Brady et al. (2009) found that juvenile weakfish Cynoscion regalis increased their swimming speed by $42 \%$. In another study, juvenile summer flounder Paralichthys dentatus increased their swimming speed with decreasing DO levels by $248 \%$ (Brady \& Targett 2010). Depending on the spatial extent of a low DO event, movement into areas with higher oxygen levels may require swimming against the current (Tyler \& Targett 2007). The overall goal of this study was to determine the impacts of hypoxia on B. chrysoura, for which there is a general lack of ecological information. Specifically, the objectives of this study were (1) to determine the lethal levels of DO using the acute sensitivity lethal concentration $\left(\mathrm{LC}_{50}\right)$ test for juvenile $B$. chrysoura, (2) examine their avoidance to low DO across different postlarval life history stages and (3) examine aerobic (endurance) swimming capacities under varying life history stages, dissolved oxygen levels, and current speeds.

\section{MATERIALS AND METHODS}

\section{Fish collection and maintenance}

Juvenile and adult Bairdiella chrysoura were collected from the estuarine portions of the LSJR with assistance from the Florida Fish and Wildlife Conservation Commission Fisheries Independent Monitoring Program (FIM). Fish were collected using 3 standard FIM gear types: a $21.3 \times 1.8 \mathrm{~m}$ center-bag seine, a $183 \times 3.0 \mathrm{~m}$ center bag seine and a $6.1 \mathrm{~m}$ otter trawl. Fish were also collected within shallow estuarine creeks ( $<1.5 \mathrm{~m}$ depth), using a $15.24 \mathrm{~m}$ center bag seine with $0.25 \mathrm{~cm}$ mesh in the wings. Immediately after collection, fish were taken back to the lab and acclimated in aquaria with conditions similar to the field. Over 7 to $14 \mathrm{~d}$, fish were acclimated with filtered seawater in aquaria with aeration and filtration to trial conditions of $28^{\circ} \mathrm{C}$ and 30 ppt salinity. Laboratory conditions were designed to mimic dry summer conditions within the LSJR and other estuarine systems. Fish were fed chopped shrimp and commercial pellet food daily until $24 \mathrm{~h}$ prior to the experiment to reduce metabolic variation among fish.

\section{Low DO acute sensitivity experiments}

Acute sensitivity tests were based on the estimated $\mathrm{LC}_{50}$ of low DO. Experiments were conducted over a $24 \mathrm{~h}$ period. Although the more conservative $96 \mathrm{~h}$ test was initially desired, it proved impractical to maintain the low oxygen levels for prolonged periods of time in small testing chambers. The tests were conducted during July and August of 2007, coinciding with historic periods of low dissolved oxygen concentrations in the field. Additional tests were conducted during June 2008.

Test containers for individual fish were 3.81 plastic aquaria. Lids were sealed to the aquaria with a port for addition and removal of test organisms as well as water measurements. Each fish was tested only once, 5 fish per oxygen treatment were used as replicates, and 3 trials were run. Five aquaria were used as controls (all conditions identical except oxygen treatment, which were kept at levels consistent with maintenance aquaria). Tested oxygen levels were 1 , $2,3,4$, and $5 \mathrm{mg} \mathrm{l}^{-1}$.

Deoxygenated water for the experiment was generated using a gas-stripping column based on the design of Barnhart (1995). We attempted to minimize disturbance to the organisms through direct bubbling of nitrogen gas in aquaria but did need to make 
periodic amendments to oxygen levels during the $24 \mathrm{~h}$ test period. No significant shifts in $\mathrm{pH}$ had been observed in earlier trials over a $24 \mathrm{~h}$ period; thus $\mathrm{pH}$ was not monitored regularly.

All trials were conducted at a salinity of $30 \mathrm{ppt}$ (1 trial had $35 \mathrm{ppt}$ ) and water temperature of between 26 and $28^{\circ} \mathrm{C}$. Experimental aquaria were set up and treatment oxygen levels were achieved before individual fish were added to the experimental aquaria. The size class (mean $\pm \mathrm{SE}, 32.5 \pm 4.0 \mathrm{~mm}$ standard length [SL]) was used to establish an a priori baseline for the following avoidance experiments because fish of this size were the most abundant size class during the time frame of the experiment. Oxygen concentrations were tested every $4 \mathrm{~h}$ for depletion below test concentrations or an increase due to air bubbles that periodically formed at the surface. Nitrogen gas was bubbled into aquaria until elevated levels were reduced to the desired treatment or air was bubbled into aquaria to raise lowered oxygen levels. After the experiment was initiated, and during oxygen adjustments, the aquaria were monitored for immobilized fish to avoid unnecessary mortality. If dead or immobilized organisms were observed, they were recorded and removed. At the end of $24 \mathrm{~h}$, immobilized or dead fish were tallied. All organisms were measured at the end of the experiment. $\mathrm{LC}_{50}$ with $95 \% \mathrm{CI}$ was determined using ToxCalc 5.0 (Tidepool Scientific).

\section{Effects of low DO on behavior and avoidance}

The preferred levels of DO for Bairdiella chrysoura were examined by partitioning a 2081 aquarium into 5 zones which allowed free movement among zones (Fig. 1A; Wu et al. 2002). The aquarium (122.5 $\times$ $32.3 \times 53.4 \mathrm{~cm}$ ) was baffled into 5 equal areas with 4 acrylic baffles measuring $30.5 \times 46.5 \mathrm{~cm}$ sealed into place $25 \mathrm{~cm}$ apart with a water depth of $48.5 \mathrm{~cm}$. The aquarium was covered with black plastic to reduce disturbance, and the top was covered with acrylic to reduce gas exchange. Fish were divided into 4 groups based on size class (mm SL): $\leq 25,26-50$, $51-75$, and $\geq 76$. For each size class, 2 trials were conducted, each with 10 replicate fish, all tested individually with each fish used only once. The first trials were conducted with normal DO concentrations (>5 $\mathrm{mg} \mathrm{l}^{-1}$ ) throughout the aquarium (control), and the second trials had a gradient from low DO concentrations $\left(<1 \mathrm{mg} \mathrm{l}^{-1}\right)$ up to high DO concentrations (>5 $\mathrm{mg} \mathrm{l}^{-1}$ ) (experimental). For the control, ambient air was bubbled into Zones 1 and 5 with air stones to create a uniform oxygen gradient in the aquarium.
For the experimental trials, nitrogen gas was bubbled into Zone 5 and ambient air was bubbled into Zone 1 to create an oxygen gradient across the aquarium. In all trials, air stones were removed after establishing a gradient to prevent any negative behavioral reaction to the air stones in Zones 1 and 5. Fish were individually acclimated to the testing aquarium in a $30.8 \times 14.5 \times 16.5 \mathrm{~cm}$ acrylic breeder box with ports on each end for $10 \mathrm{~min}$ in Zone 3 prior to being released, and each fish was used only once. The release direction of the fish was alternated between Zone 1 and Zone 5 to prevent bias in the final zone choice. After $30 \mathrm{~min}$, the ending zone, DO concentration, temperature and salinity were measured and recorded using a YSI Model 85 multimeter.

To test for a bias in the fish release direction, a 1-way ANOVA was performed on the final zone choice for the control samples released towards Zone 1 and Zone 5 for each size class. The control fish

(A) Experimental setup
\begin{tabular}{|l|c|c|c|c|}
\hline 1 & 2 & 3 & 4 & 5 \\
& & & & \\
& & & & Low \\
Normal \\
DO
\end{tabular}

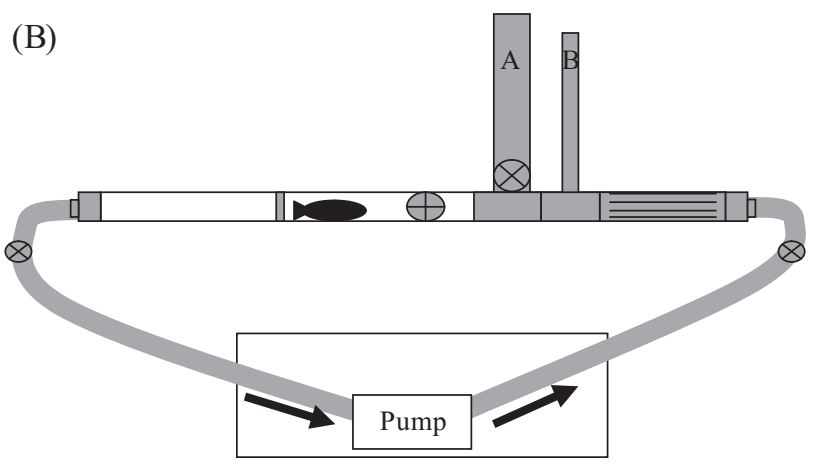

Fig. 1. (A) Partitioned aquarium allowing movement of fish throughout the entire aquarium. For control treatments, each zone had normal dissolved oxygen (DO) concentrations and the experimental groups had a gradient from normal DO concentration (Zone 1) down to low DO concentration (Zone 5). (B) Diagram of swimming speed apparatus. Arrows represent flow in/out of the water reservoir. Ambient air or nitrogen was bubbled into the water reservoir to alter the dissolved oxygen concentrations. A heater was also placed inside the reservoir to keep the temperature constant during trials. The ball valves $\otimes$ on the in/out tubing from the reservoir controlled the speed of the water, straws within the chamber produced laminar flow $\square$, and the flow meter $\oplus$ provided current speeds. 'A' represents the port in which fish were introduced into the chamber, and ' $\mathrm{B}$ ' indicates were the YSI Model 85 probe was inserted 
were unaffected by DO concentration; thus their distribution represented the expected (E) distribution, while the experimental trials with an oxygen gradient gave the observed (O) distribution (Wu et al. 2002). A chi-squared test with Yates correction factor (for small sample size) was used to determine differences in the final zone choice between the control and the experimental treatment (Zar 1999, Wu et al. 2002). A $G$-test was used to determine if there was a difference in zone choice across the size classes.

\section{Effects of low DO on swimming capacity}

To test the swimming capacity of Bairdiella chrysoura, a swimming speed apparatus was constructed based on a flow-through design with a large water reservoir to manipulate DO concentrations via bubbling ambient air or nitrogen. Water was pumped using a Mag Drive 9 submersible pump (Danner) and the chamber was $\mathrm{PVC}$, or acrylic PVC, with an inner diameter (i.d.) of $5.08 \mathrm{~cm}$ (2-inch). Straws were fastened inside the PVC to act as a flow rectifier and produce a laminar flow (or microturbulent, Plaut 2001), which was verified in the same manner as Fitzgibbon et al. (2007). Speed was controlled through ball valves going into and leaving the chamber. A YSI Model 85 probe was inserted into the first upright piece of PVC to record temperature, salinity, and DO (labeled A in Fig. 1B) and the fish were inserted into the chamber by a second upright piece of PVC (labeled B in Fig. 1B). The MIC digital flow meter (Muis Controls) was installed according to manufacturer's specifications and placed in front of the swimming fish (Fig. 1B). Fish were acclimated to the chamber for approx. $1 \mathrm{~h}$ prior to the experiment, and the experiment was deemed over once the fish touched the back of the swimming chamber (PVC with plastic mesh glued inside) 3 times or was pressed against the back without returning to a swimming position. Plastic mesh was placed inside the swimming chamber to prevent any wall effect, blocking effect, or the fish swimming too far forward in the chamber.

The 4 groups were based on size class (mm SL): $\leq 25,26-50,51-75$, and $\geq 76$. As a starting point, 3 different speeds were selected $0.17,0.25$ and $0.36 \mathrm{~m} \mathrm{~s}^{-1}$, based on LSJR flow rates, and 5 fish at each speed were run under normal DO concentrations (control, $>5 \mathrm{mg} \mathrm{l}^{-1}$ ) and low DO concentrations (experimental, 1.4 to $2.0 \mathrm{mg} \mathrm{l}^{-1}$ ). For each size class, the 2 trials were conducted with 5 replicate fish that were used only once. Control trials were run first, with ambient air bubbled into the reservoir. The experimental trials experienced low DO concentrations, created by nitrogen gas bubbled into the reservoir. Each swimming fish was timed, and the speed and DO concentrations were recorded until the experiment was deemed over. The data were analyzed with a 3-way ANOVA using the GLM procedure in SAS 9.2 (SAS Institute) for size class, current speed, and DO level, with the dependent variable as swimming time (s). A Student-Newman-Keuls (SNK) was used to determine differences in size class, current speed, and DO level. Prior to analysis, data were checked for normality and homogeneity of variances, and swimming times were $\log (\mathrm{x}+1)$ transformed to meet assumptions of ANOVA.

\section{RESULTS}

\section{Low DO acute sensitivity experiments}

The acute sensitivity tests estimated the $\mathrm{LC}_{10} \mathrm{DO}$ concentration to be $2.40 \mathrm{mg} \mathrm{l}^{-1}$ (95\% CI 1.81-3.60 mg $\mathrm{l}^{-1}$ ). The $\mathrm{LC}_{50}$ was $1.10 \mathrm{mg} \mathrm{l}^{-1}$ (95\% CI $0.43-1.52 \mathrm{mg}$ $\left.\mathrm{l}^{-1}\right)$ and the $\mathrm{LC}_{90}$ was $0.50 \mathrm{mg} \mathrm{l}^{-1}(95 \%$ CI $0.07-$ $0.88 \mathrm{mg} \mathrm{l}^{-1}$ ). Broad confidence intervals were the result of variability in DO that occurred between replicates in one trial. Throughout all 3 trials there was a $100 \%$ survivorship for the control group.

\section{Effects of low DO on behavior and avoidance}

For all 4 size classes of fish, the DO levels for the control tests showed little variance between zones with a DO of (mean $\pm \mathrm{SE}) 5.97 \pm 0.03,5.97 \pm 0.03,5.96$ $\pm 0.03,5.97 \pm 0.03,5.98 \pm 0.03 \mathrm{mg} \mathrm{l}^{-1}$ for Zones 5 to 1 , respectively. The DO levels for all experimental tests experienced a gradient from high DO down to a low DO with a DO of (mean \pm SE) $1.09 \pm 0.02,1.92 \pm 0.02$, $2.93 \pm 0.03,3.96 \pm 0.03,5.12 \pm 0.06 \mathrm{mg} \mathrm{l}^{-1}$ for Zones 5 to 1 , respectively. There was little fluctuation of DO

Table 1. Bairdiella chrysoura. ANOVA testing release direction toward Zone 1 or Zone 5 (see Fig. 1A) for all size classes $(\mathrm{mm}, \mathrm{SL})$ during normal dissolved oxygen concentration (control trials)

\begin{tabular}{|lccc|}
\hline Size class & df & $F$ & $p$ \\
\hline$\leq 25$ & 1,8 & 0.038 & 0.849 \\
$26-50$ & 1,8 & 0.167 & 0.694 \\
$51-75$ & 1,8 & 1.429 & 0.266 \\
$\geq 76$ & 1,8 & 1.440 & 0.264 \\
\hline
\end{tabular}


levels during the $30 \mathrm{~min}$ experiment, and there was never more than a $0.4 \mathrm{mg} \mathrm{l}^{-1}$ deviation in the DO levels and salinity and temperature remained constant for all tests. Release direction had no influence on the final zone choice for any of the 4 size classes (Table 1). For all size classes of the control fish, there were no significant differences in the final zone the fish selected, with an even distribution across the 5 zones (Fig. 2). Under experimental conditions, fish in the smallest size class (mean $\pm \mathrm{SE}, 24.9 \pm 0.1 \mathrm{~mm} \mathrm{SL}$ ) behaved in a significantly different manner from the control fish (chi-squared with Yates correction factor: $\chi^{2}=16.71, \mathrm{df}=4, \mathrm{p}<0.01$ ) by either remaining in Zone 3 (zone of release) or going to the zone with the highest oxygen level (Fig. 2A). Under low DO levels, very little movement was observed for fish that remained in Zone 3 . In the second size class (mean \pm $\mathrm{SE}, 29.8 \pm 0.5 \mathrm{~mm} \mathrm{SL}$ ), every fish went to the zone with the highest oxygen level $\left(\chi^{2}=40.71, \mathrm{df}=4, \mathrm{p}<\right.$ 0.001 ) (Fig. 2B). Fish from the third size class (mean \pm $\mathrm{SE}, 55.3 \pm 1.0 \mathrm{~mm} \mathrm{SL})$ selected the 2 zones with the highest oxygen levels (Fig. $2 \mathrm{C})\left(\chi^{2}=9.79, \mathrm{df}=4, \mathrm{p}<\right.$ 0.05 ). The majority of the fish $\geq 76 \mathrm{~mm}$ SL (mean $\pm \mathrm{SE}$, $96.3 \pm 2.9 \mathrm{~mm} \mathrm{SL})$ selected Zone 1 , but there was no statistical difference for this size class $\left(\chi^{2}=5.71, \mathrm{df}=\right.$ $4, p>0.05$ ) due to 2 fish selecting Zone 5 (Fig. 2D). There is a highly significant difference in the final zone choice across the size classes (G-test for independence 42.462, $\mathrm{df}=16, \mathrm{p}=0.00034$ ).

\section{Effects of low DO on swimming capacity}

At the slowest speed tested, the current was too fast for fish $\leq 25 \mathrm{~mm}$ SL and none maintained swimming position; therefore fish from the $\leq 25 \mathrm{~mm}$ SL size

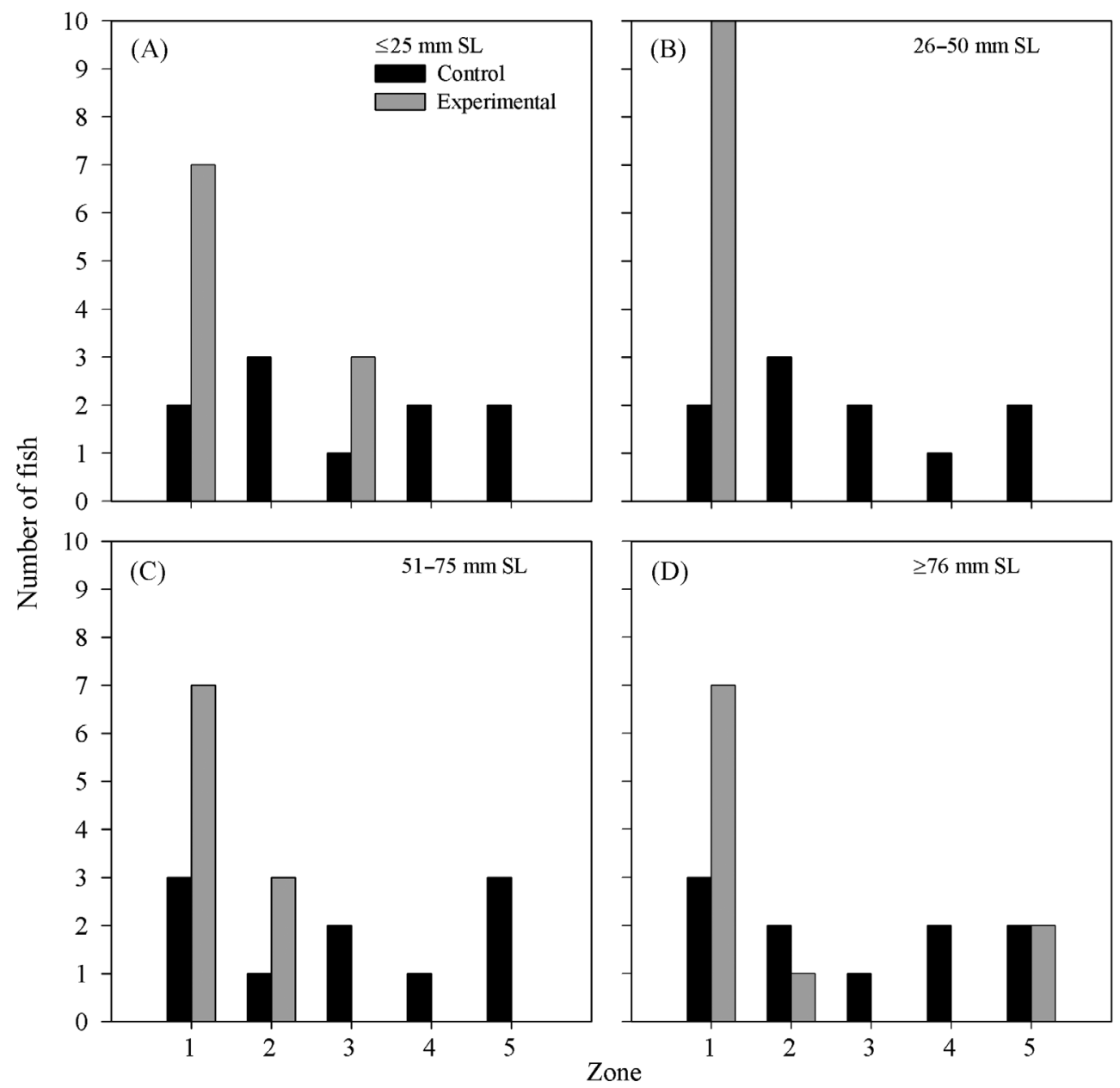

Fig. 2. Bairdiella chrysoura. Final position of fish within aquaria after $30 \mathrm{~min}$ trials for 4 size classes. Control trials had normal dissolved oxygen (DO) concentrations throughout all zones, and experimental trials had a gradient of DO from normal concentrations in Zone 1 to lowest concentrations in Zone 5. There was a significant difference in the distribution between the control and experimental treatments for the smallest 3 size classes $(p<0.01, p<0.001, p<0.05$, respectively), but not for the largest size class ( $p>0.05$ ) 
Table 2. Bairdiella chrysoura. Results of 3-way ANOVA and Student-Newman-Keuls (SNK) tests from the swimming performance experiments. SNK results for size class in $\mathrm{mm}$ (SL), speed $\left(\mathrm{m} \mathrm{s}^{-1}\right)$, and DO treatment (Low is hypoxic and High is normoxic) are listed by increasing means. Those that share a common superscript are not significantly different $(p>0.05)$

\begin{tabular}{|lrrcccc|}
\hline Effects & df & \multicolumn{1}{c|}{$F$} & \multicolumn{1}{c|}{$\mathrm{p}$} & \multicolumn{2}{c|}{ SNK results } \\
\hline Size & 2 & 83.32 & $<0.0001$ & $26-50^{\mathrm{a}}$ & $51-75^{\mathrm{b}}$ & $\geq 76^{\mathrm{c}}$ \\
Speed & 2 & 17.37 & $<0.0001$ & $0.17^{\mathrm{a}}$ & $0.25^{\mathrm{a}}$ & $0.36^{\mathrm{c}}$ \\
DO & 1 & 116.97 & $<0.0001$ & Low $^{\mathrm{a}}$ & High $^{\mathrm{b}}$ & \\
Size $\times$ Speed & 4 & 29.89 & $<0.0001$ & & & \\
Size $\times$ DO & 2 & 6.51 & $<0.0005$ & & \\
Speed $\times$ DO & 2 & 4.42 & 0.015 & & \\
Size $\times$ Speed & 4 & 11.92 & $<0.0001$ & & \\
$\quad \times$ DO & & & & & \\
\end{tabular}

class were not tested further or included in the analysis. All other size classes maintained position in the chamber under normoxic conditions. For the 3 other size classes of fish, mean salinity and temperature were consistent throughout the trials. DO levels during all control tests were maintained at normoxic levels (mean $\pm \mathrm{SD}, 5.96 \pm 0.20 \mathrm{mg} \mathrm{l}^{-1}$ ), experimental tests were maintained at hypoxic levels above the $\mathrm{LC}_{50}$ $\left(1.66 \pm 0.4 \mathrm{mg} \mathrm{l}^{-1}\right)$, and there was no mortality during the swimming speed tests. The results of the 3 main effects of size class, current speed, and DO in the 3-way ANOVA have highly significant effects on swimming time (Table 2). There is a significant difference in swimming time for the interaction of size and speed, as swimming time increases as the size class increases (Fig. 3). The interaction of fish size, current speed, and DO level is highly significant, indicating that the response in swimming performance of Bairdiella chrysoura to low DO levels will vary based on fish size and current speed (Table 2, Fig. 3). Swimming time increased as the size class increased, with larger $B$. chrysoura swimming longer at both normoxic and hypoxic DO levels. In general, with decreasing current speeds and higher DO levels, fishes had higher swimming times (Table 2, Fig. 3).

\section{DISCUSSION}

In comparison to other sciaenids that inhabit estuaries in North America, Bairdiella chrysoura has an intermediate tolerance to low DO concentrations. Juvenile red drum Sciaenops ocellatus and spotted seatrout Cynoscion nebulosus have the highest $24 \mathrm{~h}$ $\mathrm{LC}_{50}$ values for sciaenids. Sciaenops ocellatus from Florida (85.4 $\pm 6.4 \mathrm{~mm}$ total length [TL]) have a $\mathrm{LC}_{50}$

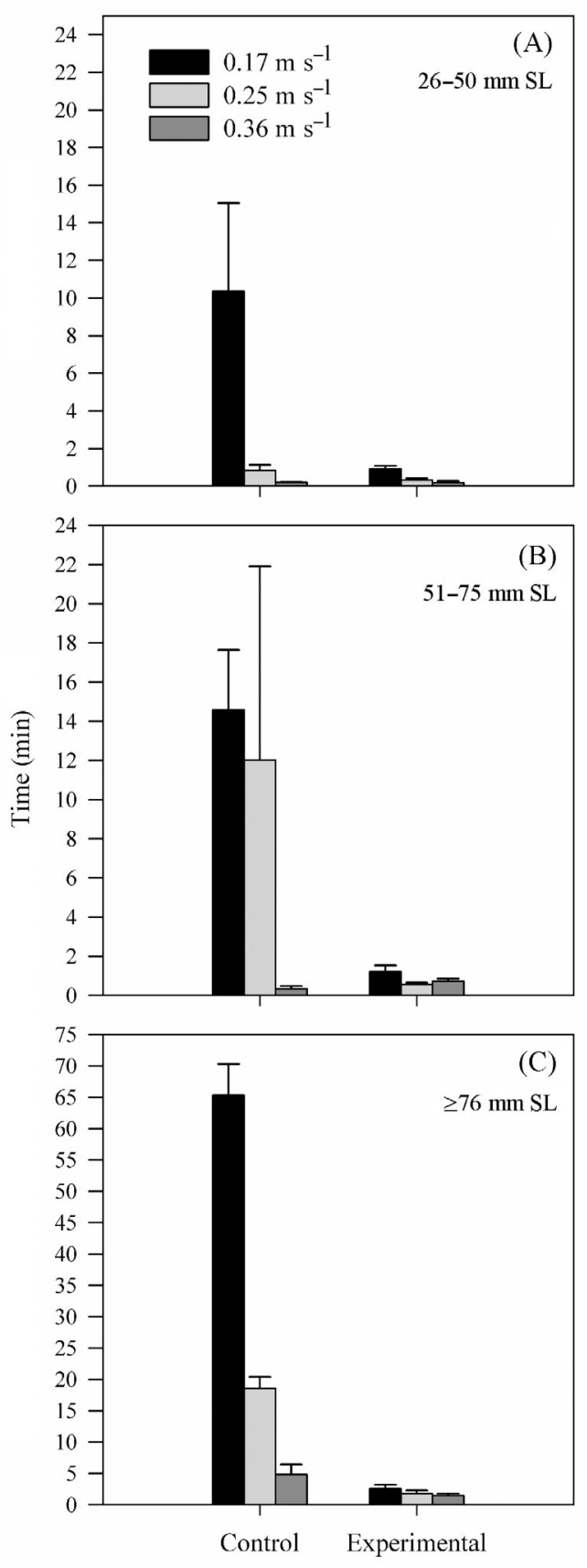

Fig. 3. Bairdiella chrysoura. Mean \pm SE swimming times of the 3 largest size classes for control (normal DO concentrations) and experimental (low DO concentrations) treatments and 3 different current speeds. At the slowest speed the current was too fast for the smallest size class and these fish were not included in the analysis

of $1.45 \mathrm{mg} \mathrm{l}^{-1}$ (CI 1.36-1.54 $\mathrm{mg} \mathrm{l}^{-1}$ ) (Goodman \& Campbell 2007), and juvenile $S$. ocellatus from the Virginian Province have an $24 \mathrm{~h} \mathrm{LC}_{50}$ of $1.4 \mathrm{mg} \mathrm{l}^{-1}$ (median CI \pm 0.3 ) (Miller et al. 2002). Cynoscion nebulosus from Texas (an $45 \pm 3.7 \mathrm{~mm}$ TL) are reported to have an $\mathrm{LC}_{50}$ at $24 \mathrm{~h}$ of $1.89 \mathrm{mg} \mathrm{l}^{-1}$ (CI 1.69-2.03 $\mathrm{mg} \mathrm{l}^{-1}$ ) 
(Goodman \& Campbell 2007). Spot Leiostomus xanthurus (at low, medium and high current speeds $87.6 \pm 9.6 \mathrm{~mm}$ TL) from the Chesapeake Bay have an $\mathrm{LC}_{50}$ at $24 \mathrm{~h}$ of $0.67 \mathrm{mg} \mathrm{l}^{-1}\left(\mathrm{CI} \pm 0.03 \mathrm{mg} \mathrm{l}^{-1}\right.$ ) (Burton et al. 1980). Bairdiella chrysoura in this experiment $(49.1 \pm 1.6 \mathrm{~mm} \mathrm{SL})$ have an $\mathrm{LC}_{50}$ of $1.10 \mathrm{mg} \mathrm{l}^{-1}$. In comparing the acute sensitivity to DO of $B$. chrysoura to other sciaenids, another difference is the size of the fishes tested in the different experiments. Goodman \& Campbell (2007) and Burton et al. (1980) use larger juvenile $S$. ocellatus and $L$. xanthurus in comparison to experiments utilizing C. nebulosus and B. chrysoura. The size discrepancy can be important since life history stage affects sensitivity to low DO (Miller et al. 2002). Utilizing multiple size classes for each species could lead to a better general understanding of response to low DO in estuarine habitats. It has been suggested that body size is independent of the ability to uptake oxygen during hypoxic conditions, and differences in uptake are often due to a life history difference (Nilsson \& Ostlund-Nilsson 2008). For example, both C. nebulosus and B. chrysoura spawn in the late spring/early summer (Rooker et al. 1998) and juveniles around $40 \mathrm{~mm}$ SL are abundant during low summer DO events in estuaries. Sciaenops ocellatus spawn September through November (Rooker et al. 1998), and therefore larger juveniles would be present during the summer low DO events. Since $S$. ocellatus and C. nebulosus have higher sensitivity to low DO concentrations, higher commercial value but a lower abundance, the more abundant $B$. chrysoura can serve as a useful model species for size-related responses to low DO concentrations.

The smallest size class of Bairdiella chrysoura (SL $\leq 25 \mathrm{~mm}$ ) is recently settled, with limited mobility and thus would be required to tolerate suboptimum physical variables. In our avoidance experiments, 3 of the 10 fish did not leave the zone of release despite a mean DO concentration of $2.87 \mathrm{mg} \mathrm{l}^{-1}$ (Fig. 2A), and fish were not able to swim against any of the tested currents in the swimming capacity experiment. Poor mobility would require a tolerance to suboptimum physical factors, as seen in with small $B$. chrysoura $(<30 \mathrm{~mm})$ that were correlated with low DO in Mississippi marshes, since small fish may not have the ability to leave areas with poor water quality (Baltz et al. 1993, Waggy 2004). The intermediate size classes of $B$. chrysoura (26-50 and 51-75 mm SL) showed strong avoidance to low DO concentrations. Fish in the largest size class (SL $\geq 76 \mathrm{~mm}$ ) were able to avoid low DO levels, yet 2 of the fish remained at the lowest level of DO (Fig. 2D). These larger fish were able to tolerate low DO concentrations for short periods of time in a lab setting (Fig. 2D), which may also be true in the field. This could enable movement into habitats experiencing low DO concentrations for short periods of time to feed on stressed benthic infauna that have evacuated their burrows (Diaz \& Rosenburg 1995, Nestlerode \& Diaz 1998), as documented in another sciaenid. Leiostomus xanthurus, a well-studied species that has been collected in trawl samples from low DO waters (Neuses River estuary, North Carolina; Bell \& Eggleston 2005). Spot also shift their diets in response to low DO, increasing their consumption of crustaceans (Chesapeake Bay, Pihl et al. 1992), an opportunistic behavior not observed for $B$. chrysoura, but there has been little research on feeding behavior for this species in northeast Florida.

Other researchers have tested avoidance behavior for several species of sciaenids using a sequence of replicated 2-way choice experiments. In these studies, croaker Micropogonias undulatus and Leiostomus xanthurus (Wannamaker \& Rice 2000) and weakfish Cynoscion regalis (Stierhoff et al. 2009) avoided water levels below $1 \mathrm{mg} \mathrm{l^{-1 }}$. However, these experiments were conducted for only one size class and response data to low DO levels across juvenile and adult size classes is lacking. Response to low DO across size classes has been examined for a freshwater fish (Burleson et al. 2001); larger size largemouth bass Micropterus salmoides avoided lower DO concentrations more effectively than smaller fish, which was attributed to predator avoidance (Savino \& Stein 1982, Ludsin \& DeVries 1997, Post 2003). Determining the response to low DO of other species across different life history stages is especially important because of the changing ecological function with changes in size class. Livingston (1988) found that estuarine fishes of different ontogenetic stages will function more similarly to different species in similar functional groups than to the same species at other life history stages. Our experiment provides evidence for the importance of size class in response to low DO, and further testing across size classes of other species is desirable.

The correlation between fish size and swimming capacity has been well documented (Bainbridge 1958, Brett 1965), and our results indicate the response in swimming performance of Bairdiella chrysoura to low DO concentrations will vary not only with fish size, but also current speed. B. chrysoura possesses poor swimming ability under low DO conditions relative to normal DO concentrations, and the response was dependent on the size class (Fig. 3). This was also demonstrated in Argyrosomus japonicas, which 
has reduced swimming capacity under decreasing DO concentrations (Fitzgibbon et al. 2007), although multiple size classes were not tested. Since all size classes were tested at the same current speeds in the present study, smaller fish were expending more effort and swimming faster in relation to the current than larger fish. While this size dependency enabled the larger fish to outperform the smaller fish (Fig. 3), it is an ecologically relevant test approach because all size classes would have to respond to reduced water quality under similar current speeds. Typically, swimming ability of fish is determined using critical swimming speed tests. The critical swimming speed $\left(U_{\text {crit }}\right)$, or maximum velocity, measures a fish's swimming performance and is often used to assess impacts of environmental conditions and pollutants (Plaut 2001). Brooks (1985) tested $U_{\text {crit }}$ with four $10 \mathrm{~g}$ silver perch at $12,16,20$, and $25^{\circ} \mathrm{C}$ under normoxic conditions and at $25^{\circ} \mathrm{C}$ a 10 gram silver perch has a $U_{\text {crit }}$ of $68.4 \mathrm{~cm} \mathrm{~s}^{-1}$. All current speeds used in this study were much slower than the $U_{\text {crit }}$ determined by Brooks (Fig 3). While the use of $U_{\text {crit }}$ could show decreased ability to swim under hypoxic conditions, the $U_{\text {crit }}$ does not take into account current speed in the estuary, how long a fish can swim at that given speed, or the time it would take to leave hypoxic regions. Within estuarine systems, currents can vary based on location and tidal cycle, and applying $U_{\text {crit }}$ for a fish that would have to move through different current regimes would not reflect these changes in swimming conditions. In addition, because $U_{\text {crit }}$ defines the maximum velocity a fish can swim, it would also be difficult to determine the duration a fish can swim at $U_{\text {crit }}$ without further retesting. In his review of the ecological relevance of critical swimming speed, Plaut (2001) states that critical swimming speeds are more useful in toxicological research than in ecological studies, such as in the present study. Using current speed as a measure to test swimming ability, in this case, has a broader ecological application since it demonstrates movement abilities of fish against river currents, determines the ability to escape a hypoxic area, and provides information for future modelling efforts (Karim et al. 2003, Hanke 2009).

Since swimming performance of Bairdiella chrysoura under low DO conditions depended upon size of the fish, and current speed, we cannot expect the outcome of a major hypoxic event to be the same for all fish size classes or for habitats with varying current speeds. While larger fish may be able to escape a rapidly developing hypoxic event caused from declining algal biomass and other confounding fac- tors (Malecki et al. 2004), this may not be true of smaller size classes. There will be size-dependent variation in movement patterns, energy expenditure, feeding responses, and predation susceptibility during low DO events. Further research is needed to understand how the different life history stages in other species respond to low DO events, which will provide a better understanding of size-specific responses to developing hypoxic events. This understanding will facilitate a more holistic approach to managing water quality for commercially and recreationally important fish species that spend multiple life history stages within potentially impaired waters.

In conclusion, Bairdiella chrysoura across all size classes relied heavily on avoidance as a main survival strategy for low DO due to a decreased swimming capacity under low DO conditions. One broad goal of this study was to address the ecological impact of hypoxia on B. chrysoura, and further research is needed to determine swimming performance of the smallest size classes using the slower current speeds in more sheltered habitats. The current speeds selected in this study were a starting point since currents had been modeled (Sucsy \& Morris 2002) for the mainstem LSJR. The mainstem was also the location of several major hypoxic events. Future research is planned to more directly assess the effects of stress on B. chrysoura caused by low DO in estuarine environments using molecular biomarker analysis. Feeding studies on field-caught individuals in both low DO and normal DO conditions may also provide insight into ecological response to low DO concentrations.

Acknowledgements. We thank D. Moon for assistance with statistical analysis and for valuable comments on earlier drafts. We thank the Florida Fish and Wildlife Conservation Commission (FWC) Fisheries Independent Monitoring (FIM) Jacksonville field lab for assistance in collecting fish, and $\mathrm{M}$. Yeager for assistance in running experiments. We also thank C. Hackney, D. Casamatta and J. Hanke. Funding for this study was provided from the University of North Florida Coastal Biology Program and from the Florida State Wildlife Grant \#SWG04-037.

\section{LITERATURE CITED}

Bainbridge R (1958) The speed of swimming of fish as related to size and to the frequency and amplitude of the tailbeat. J Exp Biol 35:109-133

Baltz DM, Rakocinski CF, Fleeger JW (1993) Microhabitat use by marsh-edge fishes in a Louisiana estuary. Environ Biol Fishes 36:109-126

> Barnhart MC (1995) An improved gas-stripping column for deoxygenating water. J N Am Benthol Soc 14:347-350

Bell GW, Eggleston DB (2005) Species-specific avoidance 
responses by blue crabs and fish to chronic and episodic hypoxia. Mar Biol 146:761-770

- Brady DC, Targett TE (2010) Characterizing the escape response of juvenile summer flounder Paralicthys dentatus to diel-cycling hypoxia. J Fish Biol 77:137-152

Brady DC, Targett TE, Tuzzolino DM (2009) Behavioral responses of juvenile weakfish (Cynoscion regalis) to diel-cycling hypoxia: swimming speed, angular correlation, expected displacement, and effects of hypoxia acclimation. Can J Fish Aquat Sci 66:415-424

Breitburg DL (1992) Episodic hypoxia in Chesapeake Bay: interacting effects of recruitment, behavior and physical disturbance. Ecol Monogr 62:525-554

Breitburg DL (2002) Effects of hypoxia, and the balance between hypoxia and enrichment on coastal fishes and fisheries. Estuaries 25:767-781

$>$ Brett JR (1965) The relation of size to rate of oxygen consumption and sustained swimming speed of sockeye salmon Oncorhynchus nerka. J Fish Res Board Can 22: 1491-1501

Brooks HA (1985) Energy utilization model for silver perch, Bairdiella chrysoura. PhDDissertation, The College of William and Mary, Williamsburg

Burleson ML, Wilhelm DR, Smatresk NJ (2001) The influence of fish size on the avoidance of hypoxia and oxygen selection by largemouth bass. J Fish Biol 59:1336-1349

> Burton DT, Richardson LB, Moore CJ (1980) Effects of oxygen reduction rate and constant low dissolved oxygen concentrations on two estuarine fish. Trans Am Fish Soc 109:552-557

> Castillo-Rivera M, Zavala-Hurtado J, Zarate R (2002) Exploration of spatial and temporal patterns of fish diversity and composition in a tropical estuarine system of Mexico. Rev Fish Biol Fish 12:167-177

Crabtree RE, Dean JM (1982) The structure of two South Carolina estuarine tide pool fish assemblages. Estuaries $5: 2-9$

Diaz RJ, Rosenburg R (1995) Marine benthic hypoxia: a review of its ecological effects and the behavioural responses of benthic macrofauna. Oceanogr Mar Biol Annu Rev 33:245-303

> Eby LA, Crowder LB (2002) Hypoxia-based habitat compression in the Neuse River Estuary: context-dependent shifts in behavioral avoidance thresholds. Can J Fish Aquat Sci 59:952-965

Fitzgibbon QP, Strawbridge A, Seymour RS (2007) Metabolic scope, swimming performance and the effects of hypoxia in the mulloway, Argyrosomus japonicus (Pisces: Sciaenidae). Aquaculture 270:358-368

FWRI (2008) Evaluations of impacts to fish communities from low dissolved oxygen episodes in the lower St. Johns River. FWRI Technical Report SWG04-037

> Goodman LR, Campbell JG (2007) Lethal levels of hypoxia for gulf coast estuarine animals. Mar Biol 152:37-42

Hanke MH (2009) Habitat utilization and the effect of hypoxia across different life history stages of silver perch (Bairdiella chrysoura) in the St. Johns River, Florida. MSc Thesis, University of North Florida, Jacksonville, FL

- Hurst TP, McKown KA, Conover DO (2004) Interannual and long-term community in the nearshore fish community of the mesohaline Hudson River Estuary. Estuaries 27: 659-669

Karim MR, Sekine M, Higuchi T, Imai T, Ukita M (2003) Simulation of fish behavior and mortality in hypoxic water in an enclosed bay. Ecol Modell 159:27-42
Kleypas J, Dean JM (1983) Migration and feeding of the predatory fish, Bairdiella chrysoura Lacépède, in an intertidal creek. J Exp Mar Biol Ecol 72:199-209

Kupschus S, Tremain D (2001) Associations between fish assemblages and environmental factors in nearshore habitats of a subtropical estuary. J Fish Biol 58: 1383-1403

La Peyre MK, Birdsong T (2008) Physical variation of nonvegetated marsh edge habitats, and use of patterns by nekton in Barataria Bay, Louisiana, USA. Mar Ecol Prog Ser 356:51-61

> Livingston RJ (1988) Inadequacy of species-level designations for ecological studies of coastal migratory fishes. Environ Biol Fishes 22:225-234

Ludsin SA, DeVries DR (1997) First-year recruitment of largemouth bass: the interdependency of early life stages. Ecol Appl 7:1024-1038

Malecki LM, White JR, Reddy KR (2004) Nitrogen and phosphorus rates from sediment in the Lower St. Johns River Estuary. J Environ Qual 33:1545-1555

McMichael RH Jr, Peters KM (1989) Early life history of spotted seatrout Cynoscion nebulosus (Pisces: Sciaenidae) in Tampa Bay, Florida. Estuaries 12:98-110

Miller D, Poucher S, Coiro L (2002) Determination of lethal dissolved oxygen levels for selected marine and estuarine fishes, crustaceans, and a bivalve. Mar Biol 140: 287-296

> Nestlerode JA, Diaz RJ (1998) Effects of periodic environmental hypoxia on predation of a tethered polychaete, Glycera americana: implications for trophic dynamics. Mar Ecol Prog Ser 172:185-195

Nilsson GE, Ostlund-Nilsson S (2008) Does size matter for hypoxia tolerance in fish? Biol Rev Camb Philos Soc 83:173-189

Peterson MS, Comyns BH, Hendon JR, Bond PJ, Duff GA (2000) Habitat use by early life-history stages of fishes and crustaceans along a changing estuarine landscape: differences between natural and altered shoreline sites. Wetlands Ecol Manage 8:209-219

Pihl L, Baden SP, Diaz RJ (1991) Effects of periodic hypoxia on distribution of demersal fish and crustaceans. Mar Biol 108:349-360

Pihl L, Baden SP, Diaz RJ, Schaffner LC (1992) Hypoxiainduced structural changes in the diet of bottom-feeding fish and Crustacea. Mar Biol 112:349-361

Plaut I (2001) Critical swimming speed: its ecological relevance. Comp Biochem Physiol A 131:41-50

Post DM (2003) Individual variation in the timing of ontogenetic niche shifts in largemouth bass. Ecology 84: 1289-1310

Rooker JR, Holt SA, Soto MA, Holt GJ (1998) Postsettlement patterns of habitat use by sciaenid fishes in subtropical seagrass meadows. Estuaries 21:318-327

Savino JF, Stein RA (1982) Predator-prey interaction between largemouth bass and bluegills as influenced by simulated, submersed vegetation. Trans Am Fish Soc 111:255-266

Stierhoff KL, Tyler RM, Targett TE (2009) Hypoxia tolerance of juvenile weakfish (Cynoscion regalis): laboratory assessment of growth and behavioral avoidance response. J Exp Mar Biol Ecol 381:S173-S179

Sucsy PV, Morris FW (2002) Calibration of a three-dimensional circulation and mixing model of the Lower St. Johns River. Tech Rep, St. Johns River Water Management District, Palatka, FL 
Tyler RM, Targett TE (2007) Juvenile weakfish Cynoscion regalis distribution in relation to diel-cycling dissolved oxygen in an estuarine tributary. Mar Ecol Prog Ser 333: 257-269

Waggy GL (2004) Life history of silver perch, Bairdiella chrysoura, from the north-central Gulf of Mexico. MSc thesis, University of Southern Mississippi, Hattiesburg

Waggy GL, Brown-Peterson NJ, Peterson MS (2006) Evaluation of the reproductive life history of the Sciaenidae in the Gulf of Mexico and Caribbean Sea: 'greater' versus 'lesser' strategies? Proc Gulf Caribb Fish Inst 57:263-281

Waggy GL, Peterson MS, Comyns BH (2007) Feeding habits and mouth morphology of young silver perch (Bairdiella

Editorial responsibility: Victor Meyer-Rochow,

Bremen, Germany chrysoura) from the north-central Gulf of Mexico. Southeast Nat 6:743-751

Wannamaker CM, Rice JA (2000) Effects of hypoxia on movements and behavior of selected estuarine organisms from the southeastern United States. J Exp Mar Biol Ecol 249:145-163

> Wu RS (2002) Hypoxia: from molecular responses to ecosystem responses. Mar Pollut Bull 45:35-45

Wu RS, Lam PK, Wan KL (2002) Tolerance to, and avoidance of, hypoxia by the penaeid shrimps (Metapenaeus ensis). Environ Pollut 118:351-355

Zar JH (1999) Biostatistical Analysis. Prentice Hall, Englewood Cliffs, NJ

Submitted: July 25, 2011; Accepted: October 13, 2011

Proofs received from author(s): November 29, 2011 